\title{
PENGARUH DIAMETER ELEKTRODA TERHADAP UJI TARIK LAS SMAW
}

\author{
THE EFFECT OF ELECTRODE DIAMETER ON TEST OF WELD SMAW
}

\author{
Moch Iqbal Mihrozi ${ }^{1 *}$, Nely Ana Mufarida, S.T., M.T. ${ }^{2}$, Kosjoko, S.T., M.T. ${ }^{3}$ \\ ${ }^{1}$ Mahasiswa, ${ }^{2}$ Dosen Pembimbing 1, ${ }^{3}$ Dosen Pembimbing 2, Program Studi Teknik Mesin, Fakultas \\ Teknik, Universitas Muhammadiyah Jember \\ "Email : iqbalmihrozi1922@gmail.com
}

\begin{abstract}
ABSTRAK
Kekuatan hasil lasan dipengaruhi oleh besar busur, besar arus, kecepatan pengelasan, besarnya penembusan dan polaritas listrik. Penentuan besar arus dalam pengelasan ini mengambil tengahtengah dari ukuran yang telah ditentukan yaitu 110 A. Pengambilan 110 A dimaksudkan sebagai pembanding dengan interval elektroda diatas. Pengujian tarik pada umumnya adalah parameter kekuatan, parameter kelihatan atau keuletan yang ditunjukkan dengan adanya persentase perpanjangan dan persentase kontraksi atau reduksi penampang. Dari data tabel dan diagram diatas dapat diketahui bahwa nilai rata-rata dari tensile strength tertinggi terdapat pada pengujian uji tarik menggunakan elektroda $(2 \mathrm{~mm})$ dengan nilai $(223,654 \mathrm{Mpa})$ sedangkan menggunakan elektroda $(2,6 \mathrm{~mm})$ mengalami penurunan nilai rata-rata sebesar $(40,654 \mathrm{Mpa})$ disebabkan oleh beberapa faktor terutama pada teknik pengelasan. Untuk nilai rata-rata upper yield strength tertinggi terdapat pada elektroda (3,2 $\mathrm{mm})$ dengan nilai $(30,647 \mathrm{Mpa})$ sedangkan nilai terendah terdapat pada elektroda $(2 \mathrm{~mm})$ dengan nilai (17,354 Mpa). Disebabkan karna hasil kekuatan las kurang sempurna.

Kata kunci: SMAW (Shielding Metal Arc Welding), Uji Tarik, E 6013
\end{abstract}

\section{ABSTRACT}

The strength of the weld is influenced by the magnitude of the arc, the magnitude of the current, the speed of welding, the magnitude of the penetration and the electrical polarity. The determination of the current in this weld takes center of the predetermined size of $110 \mathrm{~A}$. The collection of $110 \mathrm{~A}$ is intended as a comparison with the above electrode interval. Tensile testing is generally a parameter of strength, visible or ductile parameters indicated by the percentage of extension and percentage of contraction or reduction of the cross section. From the data table and diagram above it can be seen that the average value of the highest tensile strength is in the test of tensile test using electrode $(2 \mathrm{~mm})$ with value $(223,654 \mathrm{Mpa})$ while using electrode $(2,6 \mathrm{~mm})$ has decreased average value equal to (40,654 Mpa) is caused by several factors, especially on welding techniques. The highest value of upper yield strength is found in electrode $(3.2 \mathrm{~mm})$ with value $(30,647$ Mpa) while the lowest value is in electrode $(2 \mathrm{~mm})$ with value $(17,354 \mathrm{Mpa})$. The cause is the weld strength was not really perfect.

Keyword: SMAW (Shielding Metal Arc Welding), Tensile Test, E 6013

PENDAHULUAN

Pengaruh Diameter.....Moch.lqbal M.
Kekuatan hasil pengelasan dapat dipengaruhi oleh besar busur, besar arus, kecepatan pengelasan, 
besarnya penembusan dan polaritas listrik. Penentuan besarnya arus dalam penyambungan logam menggunakan las busur mempengaruhi efisiensi pekerjaan dan bahan las. Penentuan besar arus dalam pengelasan ini mengambil tengah-tengah dari ukuran yang telah ditentukan yaitu 110 A. Pengambilan 110 A dimaksudkan sebagai pembanding dengan interval elektroda diatas (Santoso, 2006). Berdasarkan latar belakang diatas maka penelitian ini mengambil judul "Pengaruh Tipe Elektroda Terhadap Uji Tarik Las SMAW".

Penelitian ini dapat diidentifikasikan berbagai permasalahan yang timbul berkaitan dengan latar belakang yang telah disebutkan, antara lain:

1. Apakah ada pengaruh terhadap kekuatan tarik daerah las besi plat $6 \mathrm{~mm}$ hasil pengelasan SMAW dengan elektroda E 6013 dengan diameter 2, 2.6 dan $3.2 \mathrm{~mm}$ ?

2. Apakah ada pengaruh terhadap kualitas kekuatan tarik baja paduan rendah hasil pengelasan SMAW dengan elektroda E 6013 dengan diameter 2, 2.6 dan $3.2 \mathrm{~mm}$ ?

Adapun masalah dalam penelitian ini dirumuskan sebagai berikut:

1. Apakah ada perbedaan hasil pengelasan dengan elektroda E 6013 dengan diameter 2, 2.6 dan 3.2 $\mathrm{mm}$ ?

2. Bagaimana cara dapat mengetahui hasil dari pengelasan elektroda E 6013 dengan diameter 2, 2.6 dan $3.2 \mathrm{~mm}$ ?

Penelitian ini menggunakan bahan baja paduan rendah yang diberi perlakuan pengelasan dengan arus 110 A dengan menggunakan las SMAW DC polaritas terbalik dalam tipe elektroda E 6013 dengan diameter 2, 2.6 dan $3.2 \mathrm{~mm}$. Jenis baja SGD $400 \mathrm{D}$ dengan plat $6 \mathrm{~mm}$ dan kampuh yang digunakan adalah kampuh V dengan sudut $70^{\circ}$ spesimen diuji tarik.

Dari perumusan masalah yang dikemukakan, maka tujuan penelitian ini adalah untuk mengetahui pengaruh pengelasan terhadap kualitas uji tarik besi plat $6 \mathrm{~mm}$ hasil pengelasan SMAW dengan kuat arus 110 A dalam tipe elektroda E 6013 dengan diameter 2, 2.6 dan $3.2 \mathrm{~mm}$.

Sebagai peran nyata dalam pengembangan teknologi khususnya pengelasan, maka penulis berharap dapat mengambil manfaat dari penelitian ini, diantaranya:

a. Sebagai literatur pada penelitian yang sejenisnya dalam rangka pengembangan teknologi khususnya bidang pengelasan. b. Sebagai informasi bagi juru las untuk meningkatkan kualitas hasil pengelasan.

Sebagai informasi penting guna meningkatkan pengetahuan bagi peneliti dalam bidang pengujian bahan, pengelasan dan bahan teknik.

\section{TINJAUAN PUSTAKA}

\section{Pengujian Tarik}

Proses pengujian tarik bertujuan untuk mengetahui kekuatan tarik benda uji. Pengujian tarik untuk kekuatan tarik daerah las dimaksudkan untuk mengetahui apakan kekuatan las mempunyai nilai yang sama, lebih rendah atau lebih tinggi dari kelompok raw materials. Pengujian tarik untuk kualitas kekuatan tarik dimaksudkan untuk mengetahui berapa nilai kekuatannya dan dimanakah letak putusnya suatu sambungan las. Pembebanan tarik adalah pembebanan yang diberikan pada benda dengan memberikan gaya tarik berlawanan arah pada salah satu ujung benda.

Penarikan gaya terhadap beban akan mengakibatkan terjadinya perubahan bentuk (deformasi) bahan tersebut. Proses terjadinya deformasi pada bahan uji adalah proses pergeseran butiran kristal logam yang mengakibatkan melemahnya gaya elektromagnetik setiap atom logam hingga terlepas ikatan tersebut oleh penarikan gaya maksimum. Pada pengujian tarik beban diberikan secara kontinu dan pelan-pelan bertambah besar, bersamaan dengan itu dilakukan pengamatan mengenai perpanjangan yang dialami benda uji dan dihasilkan kurva tegangan regangan.

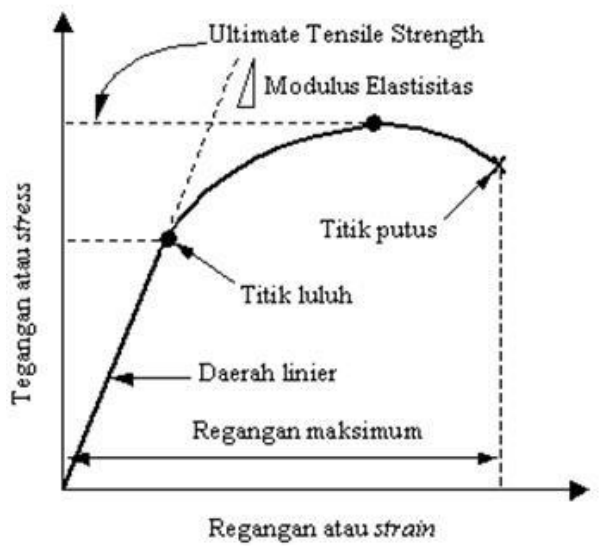

Gambar 1. Kurva Tegangan-Regangan (Santoso, 2006)

Pada pengujian tarik beban diberikan secara kontinu dan pelan-pelan bertambah besar, bersamaan dengan itu dilakukan pengamatan mengenai perpanjangan yang dialami benda uji dan dihasilkan 
kurva teganganregangan. Tegangan dapat diperoleh dengan membagi beban dengan luas penampang mula benda uji.

$$
\sigma_{U}=\frac{\mathrm{F}_{\mathrm{u}}}{\mathrm{A}_{0}}
$$

Dimana:

$\sigma_{\mathrm{u}} \quad=$ Tegangan nominal $\left(\mathrm{N} / \mathrm{mm}^{2}\right)$

$\mathrm{F}_{\mathrm{u}} \quad=$ Beban maksimal $(\mathrm{N})$

$\mathrm{A}_{\mathrm{o}} \quad=$ Luas penampang mula dari penampang batang $\left(\mathrm{mm}^{2}\right)$

Regangan (persentase pertambahan panjang) yang diperoleh dengan membagi perpanjangan panjang ukur $(\Delta \mathrm{L})$ dengan panjang ukur mula-mula benda uji.

Dimana: $\quad \varepsilon=$ Regangan $(\%)$

$$
\varepsilon=\frac{\Delta \mathrm{L}}{\mathrm{L}_{0}} \times 100 \%=\frac{\mathrm{L}-\mathrm{L}_{0}}{\mathrm{~L}_{0}} \times 100 \%
$$

$\mathrm{L}=$ Panjang akhir (mm)

$\mathrm{L}_{\mathrm{o}}=$ Panjang awal (mm)

Pembebanan tarik dilakukan terus-menerus dengan menambahkan beban sehingga akan mengakibatkan perubahan bentuk pada benda berupa pertambahan panjang dan pengecilan luas permukaan dan akan mengakibatkan kepatahan pada beban. Persentase pengecilan yang terjadidapat dinyatakan dengan rumus sebagai berikut:

$$
\mathrm{q}=\frac{\Delta \mathrm{A}}{\mathrm{A}_{0}} \times 100 \%=\frac{\mathrm{A}_{0}-\mathrm{A}_{1}}{\mathrm{~A}_{0}} \times 100 \%
$$

Dimana:

$\mathrm{q} \quad=$ Reduksi penampang $(\%)$

$\mathrm{A}_{\mathrm{o}} \quad$ = Luas penampang mula $\left(\mathrm{mm}^{2}\right)$

$\mathrm{A}_{1} \quad=$ Luas penampang akhir $\left(\mathrm{mm}^{2}\right)$

$\Delta \mathrm{A}=$ Jumlah dari $\mathrm{A}_{0}-\mathrm{A}_{1}$ (Santoso, 2006).

\section{METODE PENELITIAN}

Metode penelitian adalah suatu cara yang digunakan dalam penelitian, sehingga pelaksanaan dan hasil penelitian bisa untuk dipertanggungjawabkan secara ilmiah. Penelitian ini menggunakan metode eksperimen, yaitu suatu cara untuk mencari hubungan sebab akibat antara dua faktor yang berpengaruh.

Eksperimen dilaksanakan dilaboratorium dengan kondisi dan peralatan yang diselesaikan guna memperoleh data tentang pengaruh arus pengelasan terhadap kekuatan tarik las SMAW dalam tipe elektroda E 6013 dengan diameter 2, 2.6 dan $3.2 \mathrm{~mm}$.

\section{Diagram Alir Penelitian}

Uraian langkah-langkah penelitian diatas dapat dijabarkan ke dalam diagram alir penelitian sebagai berikut:

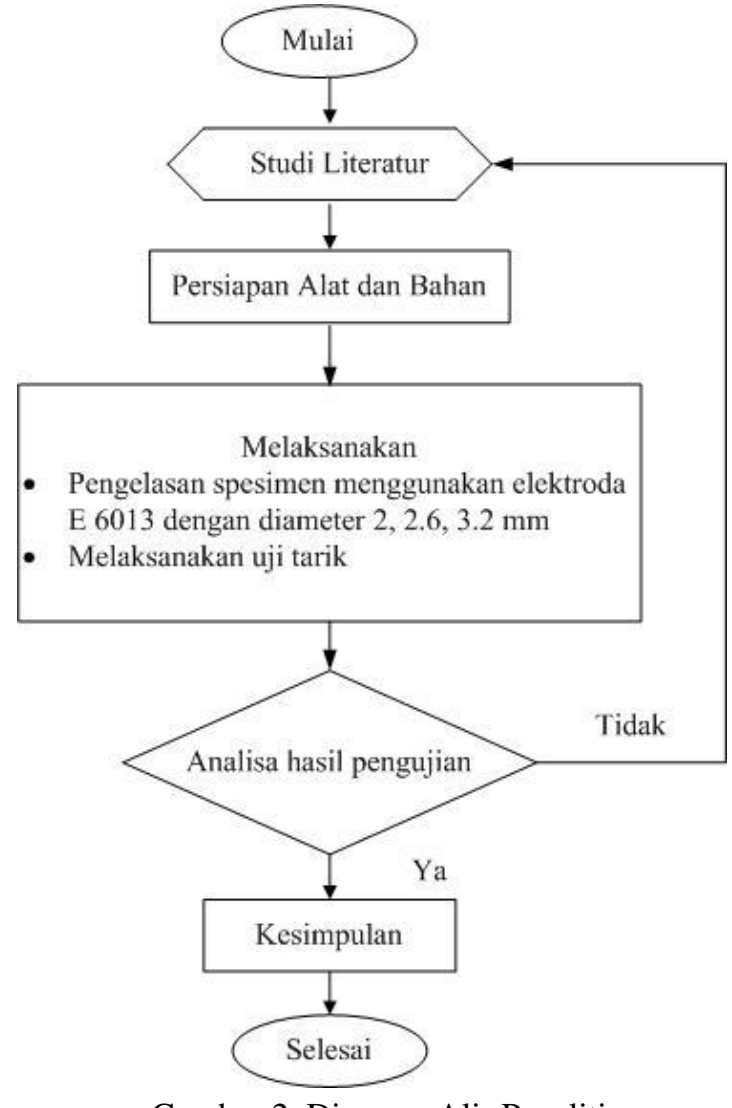

Gambar 2. Diagram Alir Penelitian

\section{HASIL DAN PEMBAHASAN \\ Tahap Pengujian}

Langkah awal pengujian ini yaitu:

1. Pembuatan kampuh $\mathrm{V}$ terbuka dengan menggunakan mesin gerinda. Bahan yang telah dipersiapkan dipotong dengan mesin gergaji, dengan ukuran $30 \mathrm{~cm}$ sebanyak 18 batang, setelah bahan dipotong kemudian permukaan digambar dengan spidol, tepi permukaan diukur sedalam dua $\mathrm{mm}$ dan di ukur sudut $35^{\circ}$. Setelah bahan digambar bahan digerinda dengan sudut $35^{\circ}$.

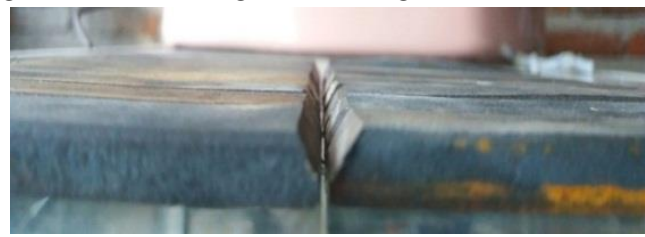

Gambar 3. Kampuh V 
2. Proses dan hasil pengelasan dengan elektroda $E$ 6013 dengan diameter $2 \mathrm{~mm}, 2.6 \mathrm{~mm}, 3.2 \mathrm{~mm}$.

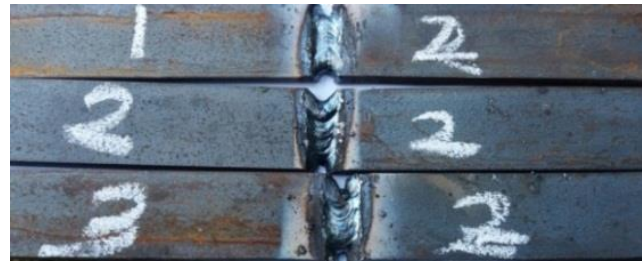

Gambar 4. Elektroda Diameter $2 \mathrm{~mm}$

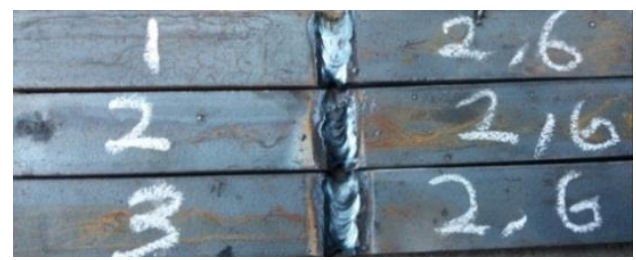

Gambar 5. Elektroda Diameter 2,6 mm

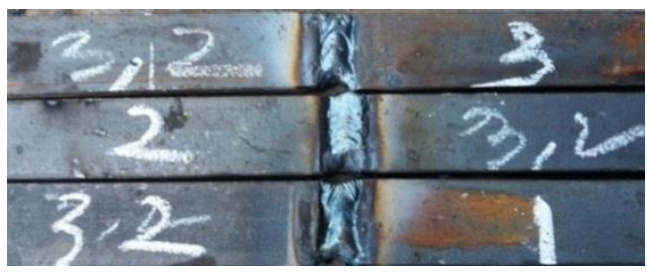

Gambar 6. Elektroda Diameter 3,2 mm

3. Pengujian dengan menggunakan mesin servopulser pada skala beban 10 ton. Spesimen pengujian terdiri dari pengujian tarik untuk kualitas kekuatan tarik baja paduan rendah hasil pengelasan SMAW dengan elektroda E 6013 dan kekuatan tarik daerah las baja paduan rendah.Data-data hasil pengujian tarik pada kelompok kelompok variasi diameter pengelasan yang sudah diperoleh kemudian dimasukkan kedalam persamaan yang ada.

\section{Hasil Pengujian}

Pengujian tarik dilakukan untuk mengetahui sifat-sifat mekanis dari material baja paduan rendah sebagai material uji dalam penelitian ini. Hasil pengujian tarik pada umumnya adalah parameter kekuatan, parameter keliatan atau keuletan yang ditunjukkan dengan adanya persentase perpanjangan dan persentase kontraksi atau reduksi penampang. Data-data tersebut selanjutnya dapat dilihat pada tabel 1 . di bawah ini.

Tabel 1. Hasil Pengujian Tarik untuk Kualitas

Kekuatan Tarik Baja Paduan Rendah

\begin{tabular}{|c|c|c|c|c|}
\hline \multirow{4}{*}{ No } & \multirow{4}{*}{ Parameter } & \multicolumn{3}{|c|}{ Spesimen } \\
\hline & & \multicolumn{3}{|c|}{ Arus 110 Ampere } \\
\hline & & E 6013 & E 6013 & E 6013 \\
\hline & & Ukuran $2 \mathrm{~mm}$ & Ukuran $2,6 \mathrm{~mm}$ & Ukuran $3,2 \mathrm{~mm}$ \\
\hline 1 & \multirow[t]{3}{*}{$\sigma_{u}(\mathrm{M}(\mathrm{pa})$} & 223,793 & 233,786 & 145,359 \\
\hline 2 & & 224,523 & 234,921 & 146,622 \\
\hline 3 & & 222,648 & 232,788 & 144,116 \\
\hline \multicolumn{2}{|r|}{ Rata-rata } & 223,654 & 233,831 & 145,365 \\
\hline 1 & \multirow[t]{3}{*}{$\sigma_{y}(\mathrm{M}(\mathrm{pa})$} & 17,117 & 30,054 & 30,383 \\
\hline 2 & & 18,521 & 31,342 & 31,612 \\
\hline 3 & & 16,425 & 29,829 & 29,948 \\
\hline \multicolumn{2}{|r|}{ Rata-rata } & 17,354 & 30,408 & 30,647 \\
\hline 1 & \multirow[t]{3}{*}{$e(\%)$} & 1 & 0,6 & 0,3 \\
\hline 2 & & 1 & 0,6 & 0,3 \\
\hline 3 & & 1 & 0,6 & 0,3 \\
\hline \multicolumn{2}{|r|}{ Rata-rata } & 1 & 0,6 & 0,3 \\
\hline
\end{tabular}

Data dari tabel 1. hasil pengujian tarik selanjutnya dimasukkan ke dalam diagram batang seperti di bawah ini:

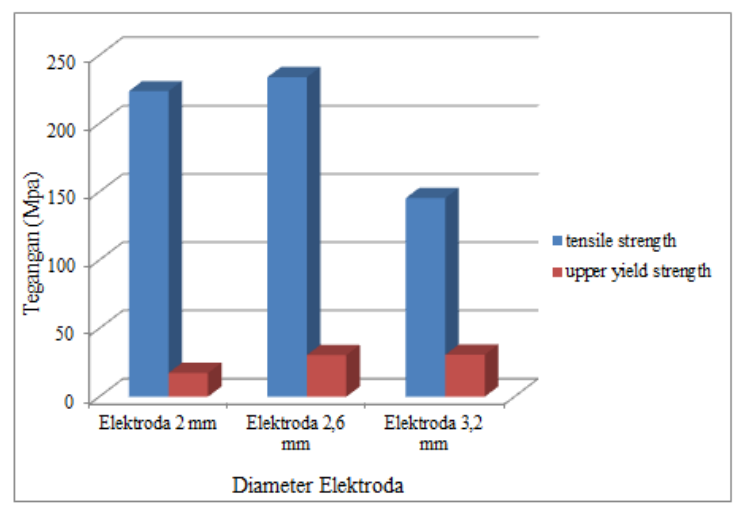

Gambar 7. Grafik Hasil Uji Tarik

Dari data tabel dan diagram diatas dapat diketahui bahwa nilai rata-rata dari tensile strength tertinggi terdapat pada pengujian uji tarik menggunakan elektroda $(2 \mathrm{~mm})$ dengan nilai $(223,654 \mathrm{Mpa})$ sedangkan menggunakan elektroda (2,6 $\mathrm{mm})$ mengalami kenaikan nilai rata-rata sebesar $(233,831$ Mpa) disebabkan oleh beberapa faktor terutama pada teknik pengelasan. Nilai rata-rata upper yield strength tertinggi terdapat pada elektroda $(3,2 \mathrm{~mm})$ dengan nilai (30,647 Mpa) sedangkan nilai terendah terdapat pada elektroda (2 mm) dengan nilai (17,354 Mpa). Disebabkan karna hasil kekuatan las kurang sempurna.

\section{PENUTUP}




\section{Kesimpulan}

Sebagaimana penulis telah menjelaskan pada hasil dan pembahasan, maka penulis dapat menarik kesimpulan sebagai berikut :

1. Nilai kekuatan yang terdapat pada pengujian tarik untuk spesimen kualitas kekuatan tarik baja paduan rendah (SGD 400 D) kelompok pengelasan dengan elektroda menggunakan diameter 2,6 $\mathrm{mm}$ menghasilkan nilai sebesar $(233,831 \mathrm{MPa})$ dapat dikatakan lebih tinggi dibandingkan kelompok variasi pengelasan dengan menggunakan elektroda berdiameter $2 \mathrm{~mm}$ dan 3,2 mm.

2. Nilai kekuatan pengujian tarik terendah terdapat pada spesimen elektroda dengan diameter 3,2 mm yaitu (145,365 Mpa). Dikarenakan pada arus yang kurang besar sehingga dapat mempengaruhi hasil dari sambungan pengelasan.

3. Hasil dari analisa uji tarik menggunakan elektroda diameter 2,6 mm, menunjukkan hasil kekuatan tarik yang cukup besar dibandingkan dengan elektroda $2 \mathrm{~mm}$ dan $3,2 \mathrm{~mm}$, karena untuk elektroda $2 \mathrm{~mm}$ arus yang di gunakan melebihi batas arus dari elektroda yaitu sebesar 65-90 A dan untuk elektroda 3,2 $\mathrm{mm}$ mengalami kekurangan arus, dimana arus yang seharusnya dipakai adalah sekitar 120-145 A.

\section{Saran}

Dari hasil penelitian ini penulis dapat memberikan beberapa saran, antara lain:

1. Perlu dilakukan penelitian lanjutan setelah selesai pengelasan hendaknya benda kerja dilakukan pasca perlakuan panas las untuk meminimalis terjadinya retak dan mengurangi tegangan sisa yang terjadi.

2. Jika mengelas dengan elektroda E 6013 dengan diameter $2 \mathrm{~mm}$ sebaiknya menggunakan arus dari 65 sampai 90, karena jika kelebihan kuat arus dapat menyebabkan busur listrik yang tejadi akan naik seketika, sehingga akan menyebabkan pencairan pada logam induk besar.

\section{DAFTAR PUSTAKA}

Jaenal Arifin, H. I. (2017). Pengaruh Jenis Elektroda Terhadap Sifat Mekanik Hasil Pengelasan SMAW Baja ASTM A36. Momentum, 27-31.

Santoso, J. (2006). Library Universitas Negeri Semarang. Retrieved April 19, 2018, from lib.unnes.ac.id: http://lib.unnes.ac.id/755/1/19 02. pdf 
